\title{
Presepsin: A Anew Marker for Early Diagnosis of Septicemia
}

\author{
HANAN H. ABD EL-LATIF, M.D.*; ASMAA O. AHMED, M.D.*; ALLA M. AHMED ATYA, M.D.** and \\ AL-SHAIMAA M. SELIM, M.Sc.* \\ The Departments of Clinical Pathology* and Anesthesiology \& ICU**, Faculty of Medicine, Assiut University, Assiut, Egypt
}

\begin{abstract}
Background: Sepsis is a life-threatening condition that arises when the body's response to an infection and injures of its own tissues and organs. The fatality rate of patients with sepsis has remained as high as $30-60 \%$ despite advances in antibiotic therapy and modern life support.
\end{abstract}

Aim of Study: Early and rapid diagnosis of septicemia by presepsin and comparing its level to the blood culture technique as a gold standard for diagnosis of septicemia.

Patients and Methods: This is a case control study. Forty five (45) post traumatic patient admitted to Intensive Care Unit (ICU) in Assiut University Hospitals who met one or more of the inclusion criteria (according to American College of Chest Physicians ACCP)/Society of Critical Care Medicine (SCCM), in addition to 15 apparently healthy subject as control group matching for age and sex. PATHFAST ${ }^{\circledR}$ Presepsin is a Chemiluminescent Enzyme Immunoassay (CLEIA) for the quantitative measurement of presepsin concentration in whole blood or plasma were used.

Results: In this study, the reference limits of presepsin were $57-337 \mathrm{pg} / \mathrm{ml}$, the sensitivity and specificity of presepsin were $97.1 \%$ and $63.6 \%$ respectively in comparing to the sensitivity and specificity of WBCs was $63 \%$ and $11 \%$ respectively and the sensitivity and specificity of hsCRP was $64 \%$ and $63 \%$ respectively. The diagnostic value in the present study were set $(879.73 \pm 403.9 \mathrm{pg} / \mathrm{ml})$ for SIRS group, (1011.19 $\pm 219.3 \mathrm{pg} / \mathrm{ml})$ for sepsis group, and $(1621.1 \pm 429.95)$ for severe sepsis group. The presepsin level was significantly increased in patients with positive blood culture (sepsis and severe sepsis group) comparing to patient with negative blood culture (SIRS group) at the time of admission and after 3 day followup. Also a significant increase in presepsin levels was observed compared to controls in the lowest to highest groups of sepsis severity during the first 3 day of intensive care treatment ( $p$ $<0.001$ ), which was not observed for WBCs and hsCRP.

Conclusion: The presepsin has a higher sensitivity and specificity in early diagnosis of sepsis as a biomarker, and its concentrations is not only useful for diagnosis of sepsis and evaluating its severity, but also used as a predictor for the prognosis of sepsis.

Key Words: Precepsin - SIRS - Sepsis - Blood culture.

Correspondence to: Dr. Asmaa O. Ahmed, E-Mail: asomar 12@yahoo.com.

\section{Introduction}

SEPSIS and septic shock are among the most important medical emergencies throughout the world. Advancement in the life support technologies have proven to be insufficient in reducing the mortality and morbidity arising from severe sepsis [1].

The 1992 statement from the American College of Chest Physicians/Society of Critical Care Medicine (ACCP/SCCM) Consensus Conference introduced into common parlance the term "Systemic Inflammatory Response Syndrome"(SIRS). The statement hypothesized that SIRS is triggered by localized or generalized infection, trauma, and thermal injury, or sterile inflammatory processes, i.e, acute pancreatitis.

Systemic Inflammatory Response Syndrome (SIRS) is the clinical syndrome that results from dysregulated inflammatory response to a noninfectious insult, such as an autoimmune disorder, pancreatitis, vasculitis, thromboembolism, burns, or surgery. It requires that two or more of the following abnormalities be present [2] .

- Body temperature $>38.5$ or $<36^{\circ}$.

- Heart rate $>90 /$ minute.

- Respiratory rate $>20 /$ minute or $\mathrm{PaCO}_{2}$ $<32 \mathrm{mmHg}$.

- Leukocyte count $>12000 / \mathrm{mm}^{3}$ or $<4000 / \mathrm{mm}^{3}$.

Sepsis: Is the clinical syndrome that results from a deregulated inflammatory response to an infection. It exists if two or more of the above abnormalities are present, along with either a culture-proven or visually identified infection [3]

Delays in the initiation of antimicrobial treatment are associated with worse prognosis, which highlights the importance of timely diagnosis to 
reduce the morbidity and mortality of sepsis patients [4]. So, early diagnosis and early treatment are essential for the clinical course and the outcome of patients with sepsis [5].

Blood Cultures (BCs) are the "gold standard" for diagnosis sepsis however, test results (identification, and antimicrobial susceptibility test results) are delayed. So, this delay has prompted the development and evaluation of rapid and molecular tests for inflammatory and other markers of infection [6].Biomarkers can have an important role in the presence, absence or severity of sepsis, also have roles in prognosis, evaluating the response to therapy and recovery of sepsis [3].

The sepsis biomarker also used to predict sepsis complications and the development of organ dysfunction (heart, kidneys, liver or multiple organ dysfunction). C-Reactive Protein (CRP) has been used for many years but its specificity has been challenged [7].

A new biomarker, presepsin or soluble cluster of differentiation-14 subtype (SCD14-ST), is proposed in the field of sepsis. It was firstly defined in 2005 and has been a new important marker for diagnosis and prognosis of sepsis in recent years

According to several studies, presepsin could be seen a valuable biomarker for early diagnosis for sepsis and distinguish it from non-infectious diseases [8]

\section{Aim of the work:}

-Early and rapid diagnosis of septicemia by presepsin level.

- Evaluation of presepsin and blood culture technique in diagnosis of septicemia.

\section{Material and Methods}

The study was conducted at Intensive Care Unit (ICU) in Assiut University Hospitals. The study was done in the Clinical Pathology Department of Assiut University Hospital, in the years from 2014 to 2015 .

Subjects were classified into two groups: Group 1 (case group): Comprised forty five patients who met one or more of the inclusion criteria according to (ACCP/SCCM) criteria Group 2 (control group): 15 apparently healthy subject as control group matching for age and sex.
Ethical approval: All subjects were informed about the aim of the study and gave their consent.

\section{Exclusion criteria:}

- The end stage diseases as malignant cancer of any type, acquired immunodeficiency syndrome, end-stage liver or renal disease.

- The patient or relatives who did not give consent to include in the study.

All patients were subjected to clinical examination including vital signs and routine investigation including: Complete Blood Count (CBC), Prothrombin Time (PT) and activated Partial Thromboplastin Time (aPTT). Liver Function Test (LFT), Kidney function test (KFT) and Random Blood Glucose (RBG). A special investigations include (blood culture, hsCRP and presepsin).

Microbiological examination: Blood culture: The blood culture set consist of a total $5: 10 \mathrm{ml}$ of blood in $10 \mathrm{ml}$ syringe and drawn on blood culture bottle of BacT/ALERT. Under complete aseptic condition with special precautions and incubated in BacT/ALERT.Blood culture samples with positive signals were processed. Subcultures were prepared on blood agar, chocolate agar, MacConkeys agar, at $37^{\circ} \mathrm{c}$ and incubated for $24-48$ hour and two Sabaroud's agar (for fungi) one at $37^{\circ} \mathrm{C}$ and the other at room temperature up to 5 days for negative result, gram stain film was made from the growth to identify type of organism (gram positive or negative, cocci or bacilli).

The identification and antibiograms: Of growing bacteria were determined with the VITEK 2 COMPACT 15 (BioMerieux, France) a fully automated system for microbial identification and Antimicrobial Susceptibility Testing (AST).

Presepsin level: Two $\mathrm{ml}$ of venous blood was collected on EDTA containing tube at the time of admission and after 3 days for follow-up, centrifugation at $3000 \mathrm{rpm}$ for 10 minutes and stored for 3 days $(2-8 c)$ or for 9 months at (-20c or lower). The Presepsin concentrations were measured by PATHFAST presepsin which is based on noncompetitive chemiluminescent enzyme immunoassay (CLEIA) combined with (MAGTRATION) technology.

\section{Statistical analysis:}

Data collected and analyzed by computer program SPSS" ver. 23" Chicago. USA.

- Data expressed as mean, standard deviation and number, percentage. 
- $t$-test or Mann-Whitney if necessary was used to determine significant for numeric variable.

- Chi. Square or Fisher exact test was used to determine significance for categorical variable.

\section{Results}

This study was performed on forty five (45) patients who met one or more of the inclusion criteria, the cases were post traumatic patient admitted to Intensive Care Unit (ICU) in Assiut University Hospitals, with age ranging from 18 to 60 years (mean \pm SD 36.4 \pm 16.67 years) in the years from 2014 to 2015 . In addition to 15 apparently healthy subject as control group matching for age and sex with age ranged from 25 to 60 years (mean \pm SD $26.33 \pm 4.31$ years). This study were done in Microbiological Unit of Clinical Pathology Department, Assiut University Hospital.

The patient groups in this study:

- Group I: Systemic inflammatory response syndrome (SIRS), 11 patients (10 males and 1 female).

- Group II: Sepsis, 21 patients (14 males and 7 females).

- Group III: Severe Sepsis, 13 patient (10 males and 3 females).

The control group in this study:

Apparently healthy persons (10 males and 5 females).

In this study there were highly significant difference $(p<0.000)$ in $\mathrm{Hgb}$ and Prothrombin Concentration (PC). Moderate significant difference $(p<0.001)$ in White Blood Cells (WBCs). Significant difference $(p<0.05)$ in platelets, Prothrombin Time (PT) and International Normalization Ratio (INR) Non significant difference about Activated Partial Thromboplastin Time (aPTT) (Table 1).

Culture positive cases 34 (76\%) which correspond to sepsis and severe sepsis and culture negative cases $11(24 \%)$ which correspond to SIRS group Fig. (1). Total number of isolate 34. Gram positive bacteria were more frequent than gram negative bacteria with frequency of $24(70.58 \%)$ and $10(29.42 \%)$ respectively. The most prevalent bacteria was klebsiella spp (26.6\%). In this study there was significant difference $(p<0.05)$ in comparing between the result of blood culture either negative or positive culture with presepsin level at admission and follow-up (Table 5), Fig. (4) with non-significant difference $(p>0.05)$ between them the presepsin level with type of organism in the blood culture either gram negative bacilli or gram positive cocci (Table 6).

In the study the results of high sensitive CRP (hsCRP) were highly significant difference ( $p$ $<0.000$ ) between cases and control groups (Table $2)$.

In this study there were highly significant difference $(p<0.006)$ of presepsin level at the time of admission in study and control groups (Table 3), Fig. (2). The presepsin level at the time of admition were significant difference $(p<0.05$ between dead and living group and highly significant difference $(p<0.000)$ between death and living groups after 3 days of follow-up (Table 4), Fig. (3).

In this study, there were highly significant difference between presepsin level and WBCs at the time of admition and follow-up and the degree of sepsis in the study group and non-significant difference between hcCRP at the time of admition and follow-up (Table 7).

The sensitivity and specificity of presepsin were $97.1 \%$ and $63.6 \%$ respectively in comparing to the sensitivity and specificity of hsCRP was $64 \%$ and $63 \%$ respectively and the sensitivity and specificity of WBCs was $63 \%$ and $11 \%$ respectively and (Table 8).

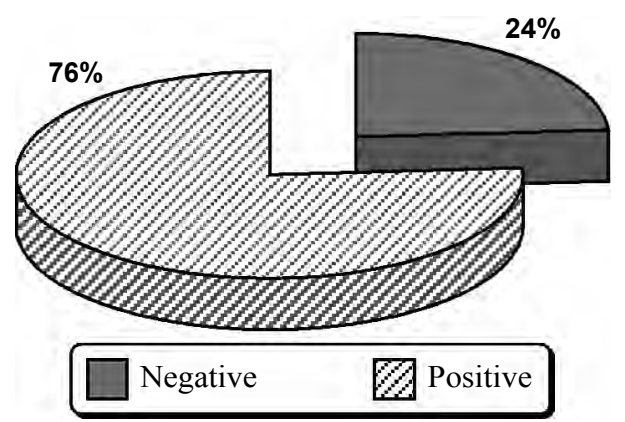

Fig. (1): Blood culture in study group.

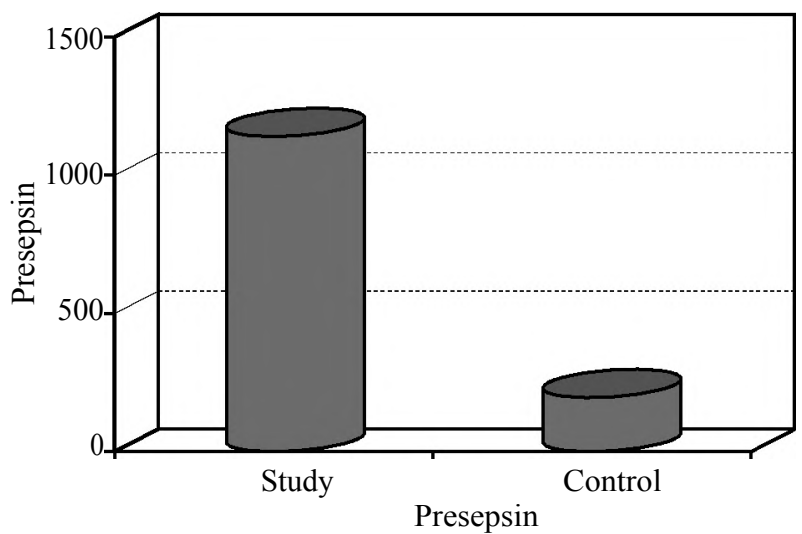

Fig. (2): Presepsin level at admission in study and control groups. 

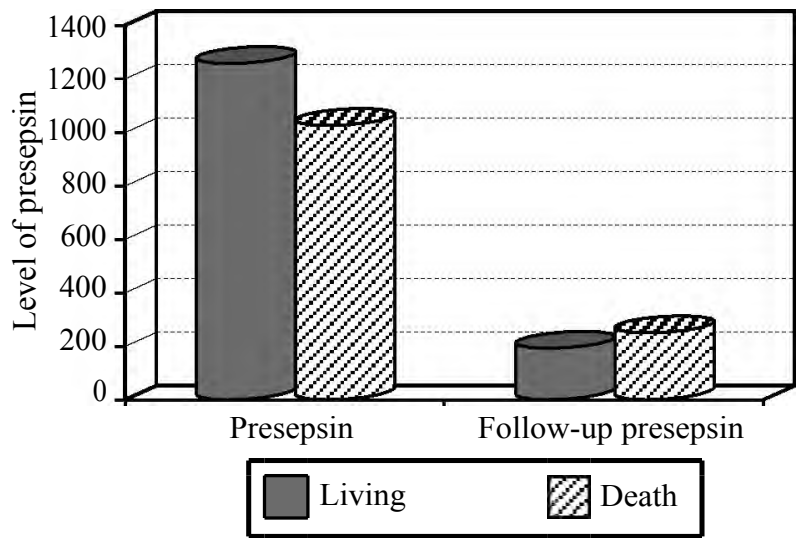

Fig. (3): The relation between presepsin levels with the outcome in study groups.

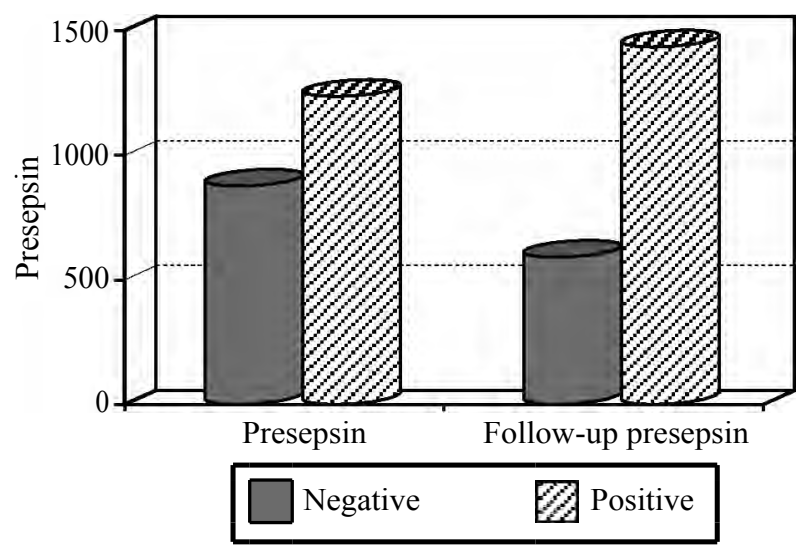

Fig. (4): Relation between presepsin with culture in study group.

Table (1): Hematological test in study and control groups (mean $\pm \mathrm{SD}$ ).

\begin{tabular}{llll}
\hline Item & $\begin{array}{c}\text { Study group } \\
(\mathrm{n}=45)\end{array}$ & $\begin{array}{c}\text { Control group } \\
(\mathrm{n}=15)\end{array}$ & \multicolumn{1}{c}{$\begin{array}{c}p- \\
\text { value }\end{array}$} \\
\hline 1- $\mathrm{WBCs}\left(\mathrm{X} 10^{9} / \mathrm{L}\right)$ & $12.77 \pm 5.84$ & $7.55 \pm 1.72$ & $p<0.001 * *$ \\
2- $\mathrm{Hgb}(\mathrm{g} / \mathrm{dl})$ & $10.03 \pm 2.08$ & $13.22 \pm 1.42$ & $p<0.000^{* * *}$ \\
3- Platelets $\left(\mathrm{X} 10^{9} / \mathrm{L}\right)$ & $189.31 \pm 89.03$ & $265.00 \pm 49.38$ & $p<0.03 *$ \\
4- PT (seconds) & $14.60 \pm 3.93$ & $12.30 \pm 0.66$ & $p<0.02 *$ \\
5- PC\% & $71.81 \pm 18.95$ & $92.11 \pm 11.34$ & $p<0.000^{* * *}$ \\
6- INR & $1.49 \pm 0.64$ & $1.03 \pm 0.06$ & $p<0.04 *$ \\
7- aPTT (seconds) & $36.68 \pm 12.87$ & $32.70 \pm 2.58$ & $p=0.243 \mathrm{n} . \mathrm{s}$ \\
\hline ns & : No statistically significant difference $(p>0.05)$. & \\
$*$ & $:$ Statistically significant difference $(p<0.05)$. & \\
** : Statistically high significant difference $(p<0.01)$. & \\
$* * *$ & : Statistically very high significant difference $(p<0.001)$.
\end{tabular}

Table (2): hsCRP and follow-up in study and control groups.

\begin{tabular}{|c|c|c|c|}
\hline Item & $\begin{array}{l}\text { Study group } \\
\quad(\mathrm{n}=45)\end{array}$ & $\begin{array}{l}\text { Control group } \\
\quad(\mathrm{n}=15)\end{array}$ & $\begin{array}{c}p- \\
\text { value }\end{array}$ \\
\hline \multicolumn{4}{|c|}{ 1- $h s C R P(m g / L):$} \\
\hline Mean \pm SD & $110.46 \pm 45.96$ & $4.42 \pm 1.42$ & $p<0.000^{* * * *}$ \\
\hline Range & $(9.80-384.0)$ & $(3.1-7.1)$ & $p<0.000^{* * *}$ \\
\hline
\end{tabular}

Table (3): Presepsin level on admission in study and control groups.

\begin{tabular}{llll}
\hline Item & \multicolumn{1}{c}{$\begin{array}{c}\text { Study group } \\
(\mathrm{n}=45)\end{array}$} & $\begin{array}{c}\text { Control group } \\
(\mathrm{n}=15)\end{array}$ & $\begin{array}{c}p \text { - } \\
\text { value }\end{array}$ \\
\hline Presepsin: $p g / m l:$ & & & \\
$\quad$ Mean $\pm \mathrm{SE}$ & $1155.6 \pm 189.29$ & $212.51 \pm 25.07$ & $p<0.006^{* *}$ \\
$\quad$ Median & 672.00 & 198.0 & \\
Range & $(211.0-4965.0)$ & $(57.0-337.0)$ & \\
\hline
\end{tabular}

Table (4): The relation between presepsin levels with outcome in study groups (mean $\pm \mathrm{SE}$ ).

\begin{tabular}{lccl}
\hline Item & $\begin{array}{c}\text { Dead } \\
(\mathrm{n}=24)\end{array}$ & $\begin{array}{c}\text { Living } \\
(\mathrm{n}=21)\end{array}$ & $\begin{array}{c}p \text { - } \\
\text { value }\end{array}$ \\
\hline 1- Presepsin $(\mathrm{pg} / \mathrm{ml})$ & $1262.2 \pm 247.86$ & $1033.6 \pm 294.60$ & $p<0.03^{*}$ \\
2- Follow-up presepsin & $2044.3 \pm 315.22$ & $256.20 \pm 12.85$ & $p<0.000^{* * *}$ \\
\hline
\end{tabular}

Table (5): Relation between presepsin with result of blood culture in study group.

\begin{tabular}{|c|c|c|c|}
\hline Item & $\begin{array}{c}\text { Negative blood } \\
\text { culture } \\
\text { SIRS } \\
(\mathrm{n}=11)\end{array}$ & $\begin{array}{l}\text { Positive blood } \\
\text { culture (sepsis, } \\
\text { severe sepsis) } \\
(\mathrm{n}=34)\end{array}$ & $\begin{array}{c}p- \\
\text { value }\end{array}$ \\
\hline $\begin{array}{l}\text { 1- Presepsin }(\mathrm{pg} / \mathrm{ml}) \text { : } \\
\text { Mean } \pm \mathrm{SE} \\
\text { Range }\end{array}$ & $\begin{array}{l}879.73 \pm 403.25 \\
(211.0-4730.0)\end{array}$ & $\begin{array}{l}1244.80 \pm 215.21 \\
(294.0-4965.0)\end{array}$ & $\begin{array}{l}p \\
<0.02 *\end{array}$ \\
\hline $\begin{array}{l}\text { 2- Follow-up presepsin: } \\
\text { Mean } \pm \text { SE } \\
\text { Range }\end{array}$ & $\begin{array}{l}601.55 \pm 251.23 \\
(117.0-2670.0) \\
p<0.03 *\end{array}$ & $\begin{array}{l}1441.50 \pm 270.04 \\
(210.0-6540.0) \\
p<0.04 *\end{array}$ & $\begin{array}{l}p \\
<0.03 *\end{array}$ \\
\hline
\end{tabular}

Table (6): Relation between presepsin with type of organism in blood culture study groups (mean $\pm \mathrm{SE}$ ).

\begin{tabular}{lccc}
\hline Item & $\begin{array}{c}\text { Gram negative } \\
\text { bacilli } \\
(\mathrm{n}=10)\end{array}$ & $\begin{array}{c}\text { Gram positive } \\
\text { cocci } \\
(\mathrm{n}=24)\end{array}$ & $\begin{array}{c}p- \\
\text { value }\end{array}$ \\
\hline 1- Presepsin $(\mathrm{Pg} / \mathrm{ml})$ & $1188.12 \pm 430.80$ & $1268.4 \pm 252.34$ & $p=0.868 \mathrm{n} . \mathrm{s}$ \\
2- Follow-up presepsin & $866.33 \pm 333.05$ & $1657.2 \pm 343.07$ & $p=0.197 \mathrm{n} . \mathrm{s}$
\end{tabular}

Table (7): Relation between presepsin, WBCs and hsCRP with degree of sepsis in study groups.

\begin{tabular}{lllll}
\hline Item & \multicolumn{1}{c}{$\begin{array}{c}\text { SIRS } \\
(\mathrm{n}=11)\end{array}$} & $\begin{array}{c}\text { Sepsis } \\
(\mathrm{n}=21)\end{array}$ & $\begin{array}{c}\text { Severe sepsis } \\
(\mathrm{n}=13)\end{array}$ & $\begin{array}{c}p \text { - } \\
\text { value }\end{array}$ \\
\hline 1- Presepsin (pg/ml) & $879.73 \pm 403.9$ & $1011.19 \pm 219.3$ & $1621.1 \pm 428.95$ & $\mathrm{Pt}<0.001 * *$ \\
2- Follow-up presepsin & $601.55 \pm 251.63$ & $942.14 \pm 210.52$ & $2315.4 \pm 577.28$ & $\mathrm{Pt}<0.005^{* *}$ \\
3- WBCs (X109/L) & $16.56 \pm 6.26$ & $12.50 \pm 5.04$ & $9.98 \pm 5.35$ & $\mathrm{Pt}<0.001 * *$ \\
4- Follow-up WBCs & $10.68 \pm 5.34$ & $11.16 \pm 4.31$ & $10.80 \pm 5.89$ & $\mathrm{Pt}<0.005 * *$ \\
5- hsCRP (mg/l) & $72.20 \pm 22.03$ & $131.29 \pm 23.42$ & $109.20 \pm 22.25$ & $\mathrm{Pt}=0.242 \mathrm{n} . \mathrm{s}$ \\
6- Follow-up CRP & $80.18 \pm 26.65$ & $99.90 \pm 14.06$ & $91.11 \pm 24.24$ & $\mathrm{Pt}=0.791 \mathrm{n} . \mathrm{s}$ \\
\hline
\end{tabular}

Pt: Comparison between SIRS, sepsis and severe sepsis. 
Table (8): The sensitivity and specificity of presepsin, hsCRP and WBCs according to the result of blood culture (as it is a gold standard for diagnosis of sepsis).

\begin{tabular}{llcc}
\hline Items & Cutoff & Sensitivity & Specificity \\
\hline Presepsin $(\mathrm{pg} / \mathrm{ml})$ & 406.71 & $97.1 \%$ & $63.6 \%$ \\
hsCRP $(\mathrm{mg} / \mathrm{L})$ & 60.0 & $64 \%$ & $63 \%$ \\
WBCs $\left(\mathrm{X} 10^{9} / \mathrm{L}\right)$ & 12.0 & 67.05 & $11 \%$ \\
\hline
\end{tabular}

\section{Discussion}

Sepsis is a life-threatening condition that arises when the body's response to an infection and injures of its own tissues and organs [9]. Despite advances in antibiotic therapy and modern life support, the fatality rate of patients with sepsis has remained as high as $30-60 \%$ [10]

In the present study, the result of blood cultures were positive in $75.6 \%$ of cases and this percentage represent sepsis and severe sepsis groups $(n=34)$, and were negative in $24.4 \%$ ( $\mathrm{n}=11$ ) which represent SIRS group.

As the conventional laboratory signs of sepsis, such as total leucocytes count, lactate, blood glucose, or thrombocyte counts, which are sensitive and easy to measure, are also very nonspecific [11]

The sensitivity and specificity of WBCs was $63 \%$ and $11 \%$ respectively, the moderate sensitivity and low specificity made difficulty to depend on WBCs as a test for diagnosis of sepsis. This low specificity due to the presence of other causes than sepsis lead to Leukocytosis as neutrophil margination in trauma or stress [12].

This result is in agreement with Muller et al., 2007 [13] who reported that the Leukocytosis is the commonly used laboratory parameter which has a low sensitivity and specificity for the diagnosis of infection.

Therefore, the development of sepsis-specific biomarkers and molecular diagnostics for the assessment of the host response and for pathogen detection is expected to faster both drug development and the improved clinical management of sepsis [14]

An ideal biomarker is still needed to accurately differentiate sepsis from non-infectious SIRS in a timely and economic manner [5].

In the present study, the sensitivity and specificity of hsCRP was $64 \%$ and $63 \%$ respectively, the moderate sensitivity and specificity made it difficult to use as a single biomarker for sepsis.
Hofer et al., [15] reported that the CRP can never use as a single diagnostic tool and its application in infectious diseases is unquestionable, not only in adults but also in pediatric patients and its low specificity may be its primary drawback as a biomarker of sepsis in adults.

Mitaka, [16] reported that the traditional markers of systemic inflammation, such as CRP, and White Blood Cell count (WBC), have proven to be of limited utility in patients with sepsis due to their poor sensitivity and specificity for bacterial infection. And the microbiological cultures; the conventional gold standard diagnostic method for sepsis, are often time consuming do not reflect the host response of systemic inflammation or the onset of organ dysfunction, and sometimes misleading with false positive or false negative reports. These shortcomings in both culture and available blood tests have driven researchers to find other more sensitive and specific markers.

A biomarker, presepsin or soluble CD14subtype (sCD14-ST), is proposed in the field of sepsis. It was firstly defined in 2005 and has been an important marker for diagnosis and prognosis of sepsis [17].

The diagnostic value in the present study were set $(879.73 \pm 403.9 \mathrm{pg} / \mathrm{ml})$ for SIRS, $(1011.19 \pm 219.3$ $\mathrm{pg} / \mathrm{ml})$ for sepsis, and $(1621.1 \pm 429.95)$ for severe sepsis, compared to presepsin level in control group were $(212.51 \pm 97.1 \mathrm{pg} / \mathrm{ml})$.

This finding is in agreement with Vodnik et al., 2013 [18] who evaluated the performance of presepsin pre-operative diagnosis of abdominal sepsis and found that presepsin was significantly higher in severe sepsis $(1508.3 \pm 866.6 \mathrm{pg} / \mathrm{mL})$ group when compared to healthy individuals $(258.7 \pm 92.53)$ and SIRS patients $(430.0 \pm 141.33 \mathrm{pg} / \mathrm{m})$.

Shirakawa et al., [8] reported that presepsin could be seen a valuable biomarker for early diagnosis for sepsis and distinguish it from noninfectious diseases. Presepsin levels in patients with sepsis were found significantly elevated in comparison with patients having Systemic Inflammatory Response Syndrome (SIRS) and healthy people.

In the present study the presepsin level was significantly increased in patent with positive blood culture (sepsis and severe sepsis group) comparing to patient with negative blood culture (SIRS group) at the time of admission and after 3 day followup. Also a significant increasing trend of presepsin levels was observed compared to controls in the 
lowest to highest groups of sepsis severity during the first 3 day of intensive care treatment ( $p$ $<0.001$ ), which was not observed for WBCs and hsCRP. This result is in agreement with Behnes et al., 2014 [19] who reported that presepsin increased significantly from the lowest to most severe sepsis groups at days 1,3 and 8 (test forlinear trend $p$ $<0.03)$.

In this study the sensitivity and specificity of presepsin were $97.1 \%$ and $63.6 \%$ respectively and this was in agreement with different studies.

Ulla et al., [20] demonstrated that the sensitivity and specificity of presepsin was $78.95 \%, 61.9 \%$ respectively, Ishikura et al., [21] also, demonstrated that the sensitivity and specificity of presepsin was 93\%, 76.3\% respectively and Behnes et al., 2014 [19] reported that the sensitivity and specificity of presepsin was $90 \%, 60 \%$ respectively.

A study from Korea, reported by OhJoo et al., 2014 who evaluated the activities of presepsin, PCT, Interleukin 6 (IL-6), and high-sensitivity CReactive Protein (hs-CRP) for their utility in the diagnosis of sepsis has revealed that among the biomarkers tested presepsin activities significantly differed in infectious $(1403.47 \mathrm{pg} / \mathrm{mL})$ and noninfectious $(239.00 \mathrm{pg} / \mathrm{mL})$ group highlighting the importance of presepsin in the diagnosis and prognosis of sepsis [22]

A multicenter prospective study conducted by Endo et al., 2014 [23] has shown that presepsin activities correlated well with the severity of sepsis at presentation and during follow-up.

In the present study all-cause mortality rates were $53.3 \%$ after 30 days (24/45) the measurements of presepsin levels revealed valuable prognostic capacity to predict short term (30-day) mortality as the level of presepsin was significantly increased in dead group comparing to living group ( $p$-value $<0.03$ ) throughout the ICU treatment and this result was in agreement with Behnes et al., [19].

Masson et al., [24] also, reported that early presepsin was higher in patients with severe sepsis or septic shock who died than in those who survived, and suggested that presepsin measurements may be of clinical importance for early risk stratification and provide useful prognostic information in these patients.

It is fast and convenient to detect sepsis and to assess the severity and prognosis of sepsis; but as a receptor, LPS is a component of the gram-negative bacterial cell wall. It is easy to imagine whether presepsin is a predicator for sepsis caused by grampositive cocci infection [25].

Masson et al., [24] evaluated that presepsin levels did not differ significantly in relation to the type of infection by either infection sites or blood cultures result (bacterial, fungal, mixed or undetermined) or by the type of bacterial infection (purely gram-negative, purely gram-positive, mixed or undetermined).

Also, Zou et al., [25] reported that the sensitivity of presepsin was not different significantly between patients with gram-positive and gram-negative bacterial infections. Additionally, the level of presepsin could be increased in patients with fungal infection, but not in patients with virus infection. In this study, there was no significant difference of presepsin level between patients with grampositive and gram-negative bacterial infections $(p$ value 0.868 ) and this is in agreement with Okamura and Yokoi, [26]. In the present study there was a positive correlation between presepsin and inflammatory biomarkers, such as CRP, but not with WBCs. This can be explained by the ongoing systemic activation of inflammatory biomarkers during severe sepsis and septic shock.

\section{Conclusion:}

- The presepsin has a higher sensitivity and specificity in early diagnosis of sepsis as a biomarker, and its concentrations is not only useful for diagnosis of sepsis and evaluating its severity, but also used as a predictor for the prognosis of sepsis.

- The clinicians must comprehensively interpret the presepsin level carefully in the context of medical history, physical examination, and microbiological assessment of patients as the presepsin level is not only sufficient to rule out sepsis.

\section{Disclosure of conflict of interest:}

The authors state that they have no conflict of interest.

\section{References}

1- DELLINGER R.P., LEVY M.M., CARLET J.M., BION J., PARKER M.M., JAESCHKE R., et al.: Surviving Sepsis Campaign: International guidelines for management of severe sepsis and septic shock, 2008.

2- ANNANE D.B.E. and CAVAILLON J.M.: Septic shock. Lancet: 363-365, 2005.

3- MARSHALL J.C. and REINHART K.: International Sepsis Forum. Biomarkers of sepsis. Crit. Care Med., 37: 2290-8, 2009.

4- LODISE T.P., Mc KINNON P.S., SWIDERSKI L. and RYBAK M.J.: Outcomes analysis of delayed antibiotic 
treatment for hospital-acquired Staphylococcus aureus bacteremia. Clin. Infect. Dis., 36: 1418-23, 2003.

5- ZANG X., LIU D., LIU Y., WANG R. and XIE I.: The accuracy of presepsin (sCD14-ST) for the diagnosis of sepsis in adults: A meta-analysis. Critical Care, 19: 323, 2015.

6- MEISNER M.: Biomarkers of sepsis: clinically useful? Curr. Opin. Crit. Povoa P., Coelho L., Almeida E., Fernandes A, Mealha R., Moreira P., Sabino H.: C-reactive protein as a marker of infection in critically ill patients. Clin. Microbiol. Infect., 11: 101-8, 2005.

7- POVOA P., COELHO L., ALMEIDA E., FERNANDES A., MEALHA R., MOREIRA P. and SABINO H.: Creactive protein as a marker of infection in critically ill patients. Clin. Microbiol. Infect., 11: 101-8, 2005.

8- SHIRAKAWA K., NAITOU K., HIROSE J., TAKAHASHI T. and FURUSAKO S.: Presepsin (sCD14-ST) development and evaluation of one strep ELISA with a new standard that is similar to the form of presepsin in septic patients. Clin. Chem. Lab. Med., 49: 937-9, 2011.

9- CZURA C.J. and MERINOFF SYMPOSIUM: Sepsisspeaking with one voice. Mol. Med., 17: 2-3, 2011.

10- DOMBROVSKIY V.Y., MARTIN A.A., SUNDERRAM J. and PAZ H.L.: Rapid increase in hospitalization and mortality rates for severe sepsis in the United States: A trend analysis from 1993 to 2003 . Crit. Care, 35: 124450, 2007.

11-LEVY M.M., et al.: 2001 SCCM/ESICM/ACCP/ATS/SIS International Sepsis Definitions Conference. Intensive Care Med., 29: 530-8, 2003.

12- ABRAMSON N. and BECKY M.: Leukocytosis: BASICS of clinical assessment' sepsis". Intensive Care Med., 32: 2077, 2000.

13- MULLER B., et al.: Diagnostic and prognostic accuracy of clinical and laboratory parameters in communityacquired pneumonia. B.M.C. Infect. Dis., 7: 10, 2007.

14- PIERRAKOS C. and VINCENT J.L.: Sepsis biomarkers: A review. Crit. Care, 14: R15, 2010.

15- HOFER N., ZACHARIAS E., MÜLLER W. and RESCH B.: "An update on the use of C-reactive protein in earlyonset neonatal sepsis: Current insights and new tasks," Neonatology, vOl. 102, No. 1, pp. 25-36, 2012.

16- MITAKA C.: Clinical laboratory differentiation of infec- tious versus noninfectious systemic inflammatory response syndrome. Clin. Chim. Acta, 351: 17-29, 2005.

17- YAEGASHI Y.S.K., SATO N., SUZUKI Y., KOJIKA M., IMAI S., TAKAHASHI G., MIYATA M., FURUSAKO S. and ENDO S.: Evaluation of a newly identified soluble CD 14 subtype as a marker for sepsis. J. Infect. Chemother., 11 (5): 234-8, 2005.

18- VODNIK T., KALJEVIC G., TADIC T. and MAJKICSINGH N.: Presepsin (sCD14-ST) in pre-operative diagnosis of abdominal sepsis. Clin. Chem. Lab. Med., 51: 2053-62, 2013.

19- BEHNES M., BERTSCH T., LEPIORZ D., LANG S., TRINKMANN F., et al.: Diagnostic and prognostic utility of soluble CD 14 subtype (presepsin) for severe sepsis and septic shock during the first week of intensive care treatment, Care, 11: 473-80, 2014.

20- ULLA, et al.: Diagnostic and prognostic value of presepsin in the management of sepsis in the Emergency Department: a multicenter prospective study. Critical Care, 17: R168, 2013.

21- ISHIKURA H., NISHIDA T., MURAI A., NAKAMURA Y., IRIE Y., TANAKA J., et al.: New diagnostic strategy for sepsis-induced disseminated intravascular coagulation: A prospective single-center observational study. Crit. Care, 18: R19, 2014.

22- KWEON O.J., CHOI J.H., PARK S.K. and PARK A.J.: Usefulness of presepsin (sCD14 subtype) measurements as a new marker for the diagnosis and prediction of disease severity of sepsis in the Korean population. Journal of Critical Care Available online 21 June, 2014.

23- ENDO S.H., SUZUKI Y., TAKAHASHI G., SHOZUSHIMA T., ISHIKURA H. and MURAI A.: Presepsin as a powerful monitoring tool for the prognosis and treatment of sepsis: A multicenter prospective study. Journal of Infection and Chemotherapy Volume 20, Issue 1, Pages 30-34. factor-alpha. Crit. Care Med., 27: 1303-8, 2014.

24- MASSON S., CAIRONI P., SPANUTH E., et al.: Presepsin (soluble CD 14 subtype) and procalcitonin levels for mortality prediction in sepsis: Data from the Albumin Italian Outcome Sepsis Trial. Crit. Care, 18: R635, 2014.

25- ZOU, et al.: Presepsin as anovel sepsis biomarker, World J. Emerg. Med., Vol. 5, No. 1, 2014.

26- OKAMURA Y. and YOKOI H.: Development of a pointof-care assay system for measurement of presepsin (sCD14-ST). Clin. Chim. Acta., 412: 21, 2011. 


\section{دور البريسيبسين فى التشخيص المبكر لتسمم الدم}

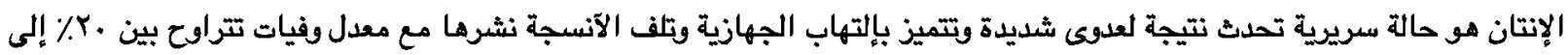

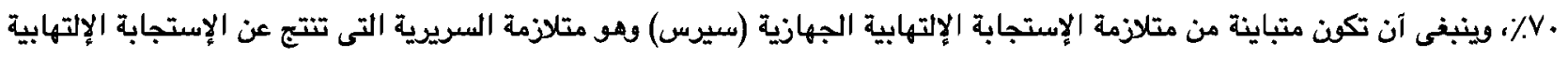

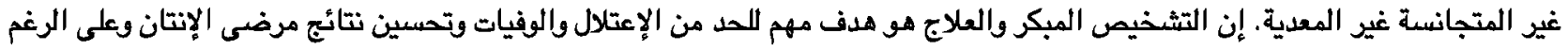

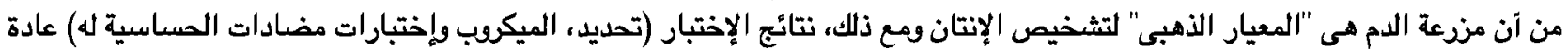

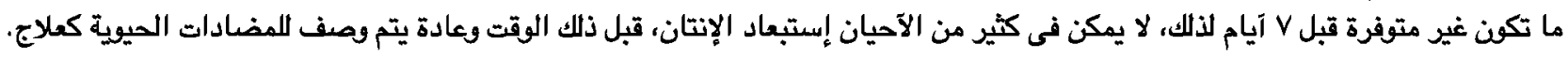

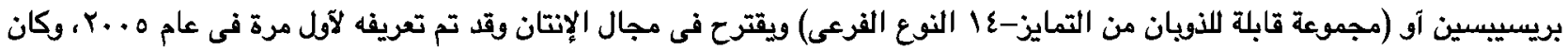
علامة هامة جديدة لتشخيص وتوقع الإنتان فى السنوات اللمات الآخيرة.

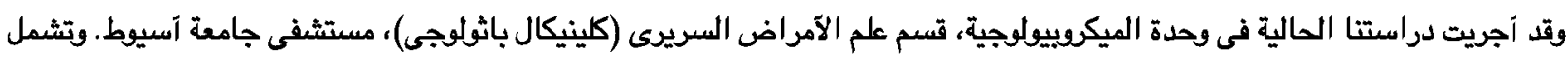

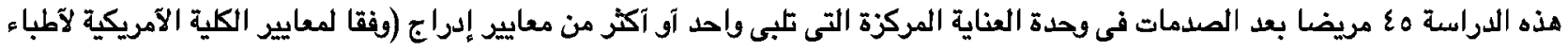

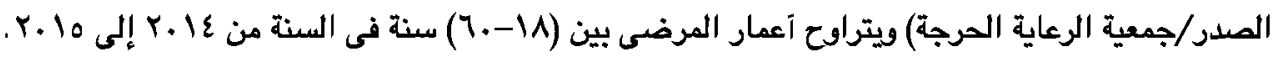

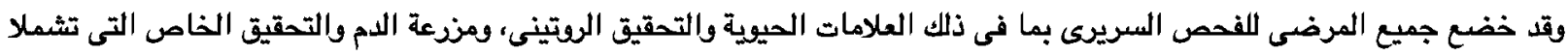

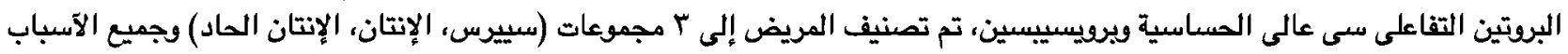

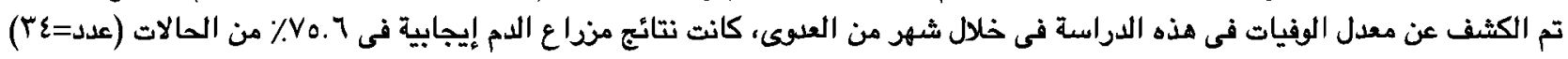

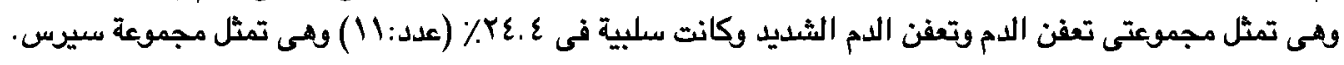

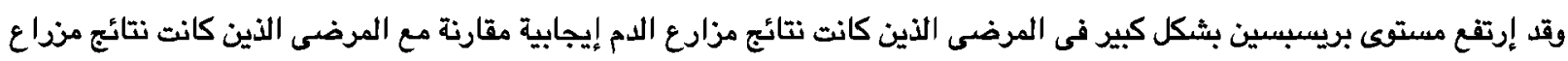

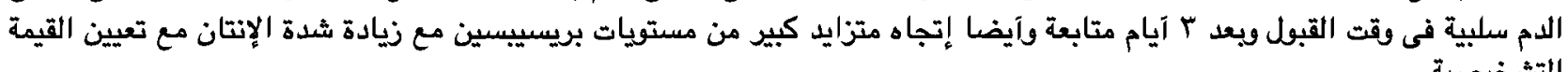

